\title{
Phylogenetic Relationships of the Family Agamidae (Reptilia: Iguania) Inferred from Mitochondrial DNA Sequences
}

\author{
Masanao Honda ${ }^{1 *}$, Hidetoshi Ota ${ }^{2}$, Mari Kobayashi ${ }^{1}$, Jarujin Nabhitabhata ${ }^{3}$, \\ Hoi-Sen Yong ${ }^{4}$, Showichi Sengoku ${ }^{5}$ and Tsutomu Hikida ${ }^{1}$ \\ ${ }^{1}$ Department of Zoology, Graduate School of Science, Kyoto University, Sakyo, Kyoto, 606-8502 Japan, \\ ${ }^{2}$ Tropical Biosphere Research Center, University of the Ryukyus, Nishihara, Okinawa, 903-0213 Japan, \\ ${ }^{3}$ National Science Museum, Rasa Tower, Fl 16, 555 Phahonyothin Road, Bangkok, 10900 Thailand, \\ ${ }^{4}$ Department of Zoology, University of Malaya, Kuala Lumpur, 59100 Malaysia, and \\ ${ }^{5}$ Japan Wildlife Research Center, Yushima, Bunkyo, Tokyo 113-0034, Japan
}

\begin{abstract}
Phylogenetic relationships of the family Agamidae were inferred from 860 base positions of a mitochondrial DNA sequence of $12 S$ and 16S rRNA genes. Results confirmed the monophyly of this family including Leiolepis and Uromastyx (Leiolepidinae), and indicated the sister relationship between Agamidae and Chamaeleonidae. Our results also indicated the presence of two major clades in Agamidae. In one of these major clades, "Leiolepidinae" was first diverged, followed by the Lophognathus and Hypsilurus in order, leaving Physignathus, Chlamydosaurus and Pogona as monophyletic. This result contradicts the currently prevailing hypothesis for the agamid phylogeny, which, on the basis of morphological data, assumes the primary dichotomy between Leiolepidinae and the remainder (Agaminae). The phylogenetic diversity of agamid lizards in the Australian region is supposed to have increased through an in situ continental radiation rather than through multiple colonizations from Southeast Asia. Distributions of some species in Asia and Melanesia are attributed to the secondary dispersals subsequent to this radiation.
\end{abstract}

\section{INTRODUCTION}

The family Agamidae (sensu lato) is the Old World counterpart of the New World Iguanidae (sensu lato). Lizards in these two families exhibit remarkable similarities in morphological structure, behavioral pattern and ecological exploitation (Stamps, 1977; Avery, 1982). Although they seem to provide excellent material for the comparative study of evolutionary processes, agamids are still poorly understood as compared to iguanids (e.g., Mori and Hikida, 1993).

Phylogeny and classification of the family Agamidae have been controversial (e.g., Moody, 1980, 1983; Böhme, 1982; Frost and Etheridge, 1989; Joger, 1991; Lazell, 1992; Schwenk, 1994; Macey et al., 1997). In his unpublished dissertation, Moody (1980), on the basis of morphological characters, divided Agamidae (sensu lato) into six groups (Fig. 1): Group I consisting of two relatively primitive, large, terrestrial and herbivorous genera Leiolepis and Uromastyx; Group II consisting of two relatively primitive, large, arboreal or aquatic, and herbivorous genera Hydrosaurus and Physignathus; Group III consisting of several terrestrial genera derived from an Australian radiation; Group IV consisting of the Melanesian

\footnotetext{
* Corresponding author: Tel. +81-75-753-4091; FAX. +81-75-753-4114. E-mail.panda@zoo.zool.kyoto-u.ac.jp
}

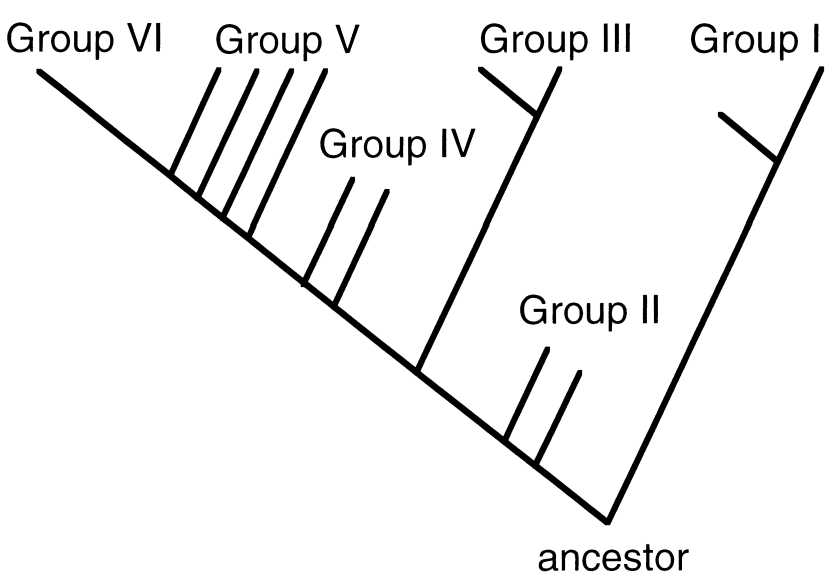

Fig. 1. Phylogenetic relationships of the Agamidae (sensu lato) proposed by Moody (1980). Group I, relatively primitive, large, terrestrial and herbivorous genera (=Leiolepidinae in Frost and Etheridge [1989]); Group II, the relatively primitive, large, arboreal or aquatic and herbivorous agamids; Group III, terrestrial agamids in the Australian region; Group IV, the Melanesian and Australian arboreal agamids; Group V, the diverse genera of primarily arboreal agamid of the tropical Asia; Group VI, the terrestrial and saxicolous radiation of the Agamid in the savannas and deserts of Africa and Asia.

and Australian arboreal genus Hypsilurus; Group V consisting of diverse, primarily arboreal genera from South and Southeast Asia; and Group VI consisting of the terrestrial and 
saxicolous genera from the arid regions of Africa and West Asia. His analysis using the unweighted Wagner tree algorithm (Farris, 1970), while showing the possible non-monophyly in the Groups II, IV and V, suggested the primary divergence of the Group I, followed by the Group II, the Group III and the Group IV in order, leaving the Groups V and VI as monophyletic (Fig. 1). He also conducted two other analyses, weighted Wagner analysis (Farris, 1969) and compatibility analysis (Estbrook et al., 1977), but resultant topologies were unstable.

Frost and Etheridge (1989), in the comprehensive revision of the infraoder Iguania, while dividing Iguanidae into eight families (Corytophanidae, Crotaphytidae, Hoplocercidae, Iguanidae [sensu stricto], Opluridae, Phrynosomatidae, Polychridae and Tropiduridae), lumped the agamid lizards with chameleons as the family Chamaeleonidae. They recognized three subfamilies, Agaminae (=Groups II-VI: Moody, 1980), Leiolepidinae (=Group I) and Chamealeoninae in this family. Although they indicated the monophyly of these acrodont lizards (agamines, leiolepidines and chameleons), they failed to elucidate their relationships.

Karyological studies sometimes give useful information for the classification of agamid lizards (e.g., Sokolovsky, 1974; Kupriyanova, 1984; Moody and Hutterer, 1978; Ota, 1988; Ota et al., 1992; King, 1990). However, recent karyological surveys (e.g., Ota, 1989a,b; Ota and Hikida, 1989) indicated that it is difficult to resolve the phylogenetic relationships among agamids by this approach due to the scarcity of phylogenetically informative characters in chromosome morphology.

We analyzed the phylogenetic relationships within Acrodonta (i.e., agamines, leiolepidines and chameleons sensu Frost and Etheridge [1989]) on the basis of mitochon- drial DNA sequence data. Such an approach is expected to be especially useful to resolve the relationships of organisms like acrodont lizards that have few phylogenetically informative morphological and karyological characters. Our purposes are: (1) to test the monophyly and infer the phylogenetic relationships of the acrodont subfamilies recognized by Frost and Etheridge (1989); (2) to assess Moody's (1980) phylogenetic hypothesis of the agamid genera and, when necessary, to designate an alternative hypothesis; and (3) to discuss the historical biogeography of agamids on the basis of the best fitting hypothesis determined through the above process.

\section{MATERIALS AND METHODS}

\section{Samples analyzed}

Tissues were obtained from 18 species in 17 genera representing the six major agamid groups of Moody (1980) (Groups I-VI), and one genus of the Chamaeleonidae (Table 1, see Appendix 1 for further details). We also incorporated into the analyses the published data (Honda et al., 1999a; Ota et al., 1999: Table 1). Although we examined only one chameleon (Bradypodion fischeri) in the present study, its designation as the representative of all chameleons should not lead to any substantial error in the results of the analyses, because the monophyly of this taxon, supported by a number of synapomorphs, deserves no doubt (e.g., Rieppel, 1981; Frost and Etheridge, 1989). We also examined samples of Anolis carolinensis of the Polychridae and Iguana iguana of the Iguanidae (sensu Frost and Etheridge, 1989), because these families are supposedly closest to the two acrodont families (Frost and Etheridge, 1989; Macey et al., 1997)

\section{DNA extraction, amplification and sequencing}

Extraction, amplification and sequencing of DNA are described in detail elsewhere (Honda et al., 1999a, b). A part of mitochondrial $12 S$ and $16 \mathrm{~S}$ rRNA genes consisting of approximately 860 base pairs (bp) were amplified using the polymerase chain reaction (PCR; Saiki

Table 1. Infrafamilial groups of the Agamidae defined in the previous studies and localities. Data sources are (A) present study; (B) Honda et al. (1999a); (C) Ota et al. (1999). See Appendix 1 for detailed localities and DDBJ accesion numbers. Asterisks denote Iguanidae (sensu lato).

\begin{tabular}{lllc}
\hline \multicolumn{1}{c}{ Sample } & Group & & Reference \\
\hline Acanthosaura crucigera & V & Thailand & A \\
Agama stelio & VI & West Asia or North Africa & A \\
Aphaniotis fusca & V & Peninsular Malaysia & B \\
Calotes versicolor & V & Thailand & A \\
Chlamydosaurus kingii & III & Australia & A \\
Draco volans & V & Java & B \\
Gonocephalus grandis & V & Peninsular Malaysia & A \\
Hypsilurus godeffroyi & IV & New Guinea & A \\
Japalura polygonata & V & Japan & A \\
Leiolepis belliana & I & Thailand & A \\
Lophognathus temporalis & III & Australia & A \\
Phoxophrys nigrilabris & V & Borneo & A \\
Phrynocephalus axillaris & VI & West Asia & A \\
Physignathus cocincinus & II & Thailand & A \\
Physignathus lesueurii & II & New Guinea & A \\
Pogona vitticeps & III & Australia & A \\
Ptyctolaemus phuwuanensis & V & Thailand & B \\
Uromastyx aegyptia & I & West Asia or North Africa & A \\
Bradypodion fischeri & Chamaeleonidae & Africa & A \\
Anolis carolinensis & Polychridae* & Japan & A \\
lguana iguana & Iguanidae* & America & C \\
\hline
\end{tabular}


et al., 1988) with primers L1091, H1478, L2606, and H3056 (Kocher et al., 1989; Hedges et al., 1993).

\section{Phylogenetic analyses}

Alignments for DNA sequences were determined based on maximum nucleotide similarity using CLUSTAL W 1.4 (Thompson et al., 1994) with default gap penalties. The output was later adjusted by eye using manual alinger SeqApp 1.9 (Gilbert, 1993) according to secondary structures of rRNA genes. However, the resultant secondary structures (not given) were unstable because of lack of information on secondary structures in closely related taxa (Titus and Frost, 1996). Thus we use the data for 652 sites based on maximum similarity excluding insertions and deletions in the following analyses, although topologies derived from these two alignments are identical. This designation should involve any substantial error in the results of the analyses.

The neighbor-joining (NJ) method (Saitou and Nei, 1987) was applied to infer relationships among taxa on the basis of a pairwise matrix of the distance from Kimura's (1980) two-parameter model. Degrees of supports for internal branches in each tree were assessed by 1,000 bootstrap pseudoreplications (Felsenstein, 1985). The NJ analysis was performed by use of CLUSTAL W. Maximum-likelihood $(\mathrm{ML})$ analysis was also conducted using fastDNAml 1.0.6 (Olsen et al., 1993). Jumble options were used to find a true ML tree. For the maximum-parsimony (MP) analysis, PAUP* 4.0b (Swofford, 1998) with heuristic option was used. The confidence was assessed by 1,000 bootstrap resamplings. In these three analyses, no bias was assumed between transition and transversion.

Morphological analysis, using PAUP* with heuristic option, was also conducted on the basis of 122 characters listed in Moody (1980). Morphological data were also analyzed in combination with DNA sequences. To combine two data sets, we adjusted 60 operational taxonomic units (OTUs) examined in Moody (1980) to 19 OTUs examined in the DNA analyses, and designated the chameleon as a presumptive outgroup on the basis of the results of analyses with molecular data alone (see below). The partition homogeneity test (Farris et al., 1994) was conducted to assess the homogeneity between DNA sequence and morphological data using PAUP* with heuristic 1,000 bootstrappings. Templeton's (1983) test, a two-tailed Wilcoxon signed ranks test (Felsenstein, 1985), was applied to examine statistical significance of the shortest tree generated from two data sets using MacClade 3.08a (Maddison and Maddison, 1992).

The interpretation of bootstrap proportions (BPs) is still in a state of uncertainty (see Felsenstein and Kishino, 1993; Hillis and Bull, 1993). We tentatively followed Shaffer et al. (1997), and considered BPs $\geq 90 \%$ as highly significant, $70 \leq \mathrm{BPs}<90 \%$ as marginally significant, and BPs $<70 \%$ as constituting limited evidence of monophyly. For the $\mathrm{ML}$ analysis and other statistics, significance level was set at $\mathrm{P}<1 \%$ to avoid type I errors.

\section{RESULTS}

\section{Mitochondrial sequence variation}

Aligned sequences from 12S and 16S rRNA genes are presented in Appendix 2. All sequences showed strong bias against guanine on the light strand $(A=33.6-37.7 \%$, $C=21.3-27.2 \%, G=17.9-20.0 \%, T=18.7-25.3 \%)$. Several observations demonstrated that such a bias represents that in mitochondrial genome, not in the nuclear integrated copies of mitochondrial genes (e.g., Zhang and Hewitt, 1996; Macey et al., 1997). We thus interpreted these sequences as those of authentic mitochondrial DNA.

The percentage of transitions with total sequence is plotted against that of transversions in Fig. 2A. Transitions
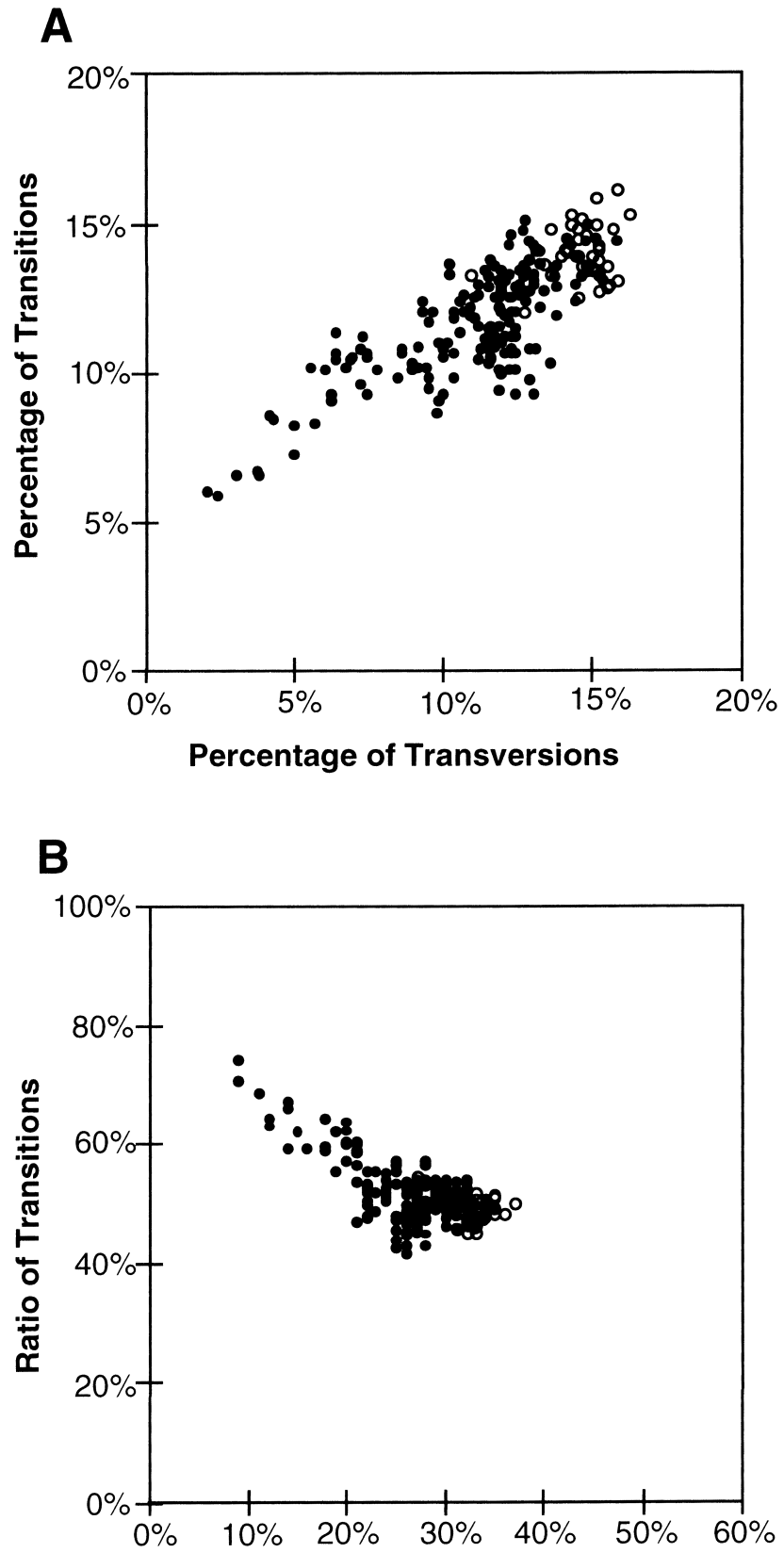

Percentage of Sequence divergence

Fig. 2. (A) Percentage of transitions with total sequence versus that of transversions for 12S and 16S rRNA genes in the 21 taxa examined. Closed circles denote comparisons within Acrodont (i.e., agamines, leiolepidines and chameleons). Open circles denote comparisons between Acrodont and outgroups. (B) Percentage of transitions with the variation versus that of sequnece divergence.

exceeded transversions at low levels of sequence divergence. This agrees with previous studies on animal mitochondrial DNA that reported an initial high $(>50 \%)$ transition bias which gradually decreases over time (Brown et al., 1982; Hedges et al., 1991; Fuller et al., 1998). The percent of transition is plotted against the total sequence divergence in Fig. 2B. The scatter plots did not exhibit a transition plateau (usually corresponding to $40-50 \%$ transitions), which is the point where multiple 
substitutions are occurring at the same site (Brown et al., 1982; Thomas et al., 1989; Hedges et al., 1991). Therefore, these data are considered to be useful for phylogenetic inference (e.g., Brown et al., 1982; Fuller et al., 1998).

The 12S rRNA fragment consisted of 423 total sites,
326 of which were variable. For the 16S rRNA fragment, there were 437 total aligned sites, 272 of which were variable. Inter-generic nucleotide replacements within Agamidae varied from $70 \mathrm{bp}$ (Physignathus lesueurii vs. Pogona) to $236 \mathrm{bp}$ (Aphaniotis vs. Leiolepis).

\section{A}

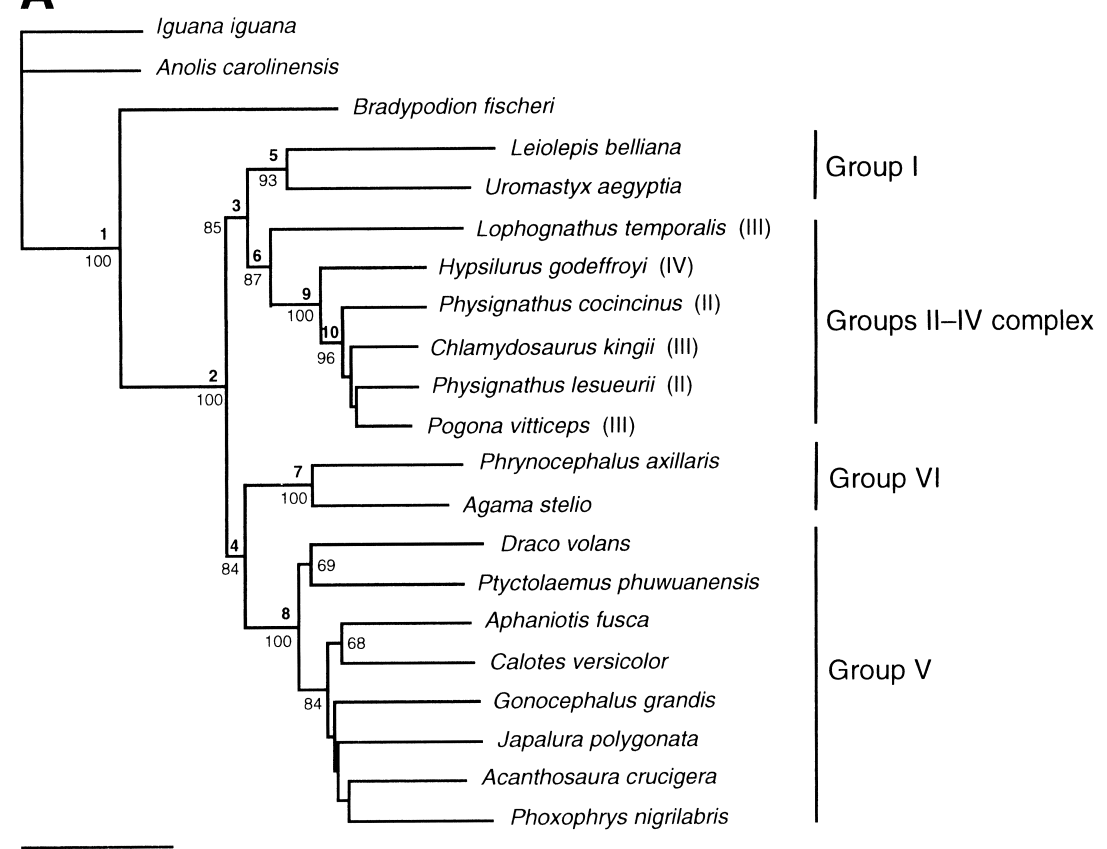

0.1

B

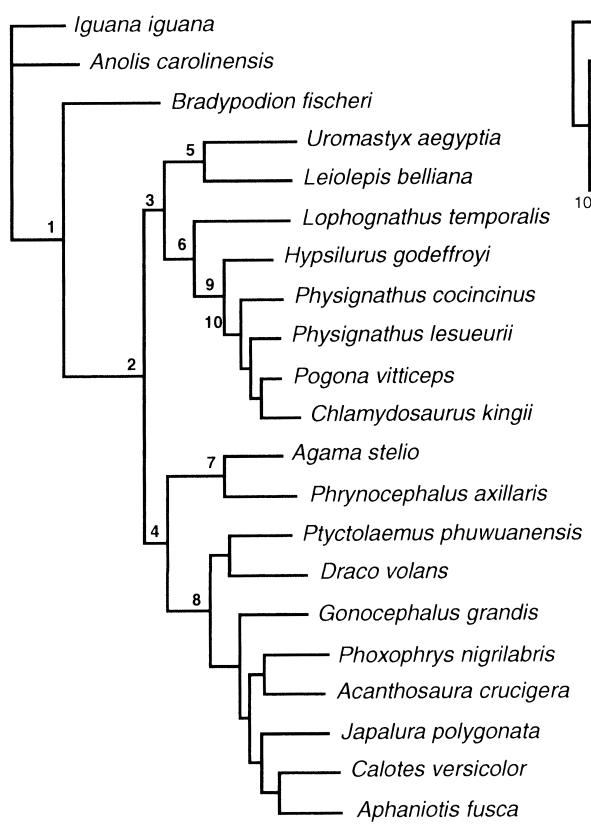

\section{C}

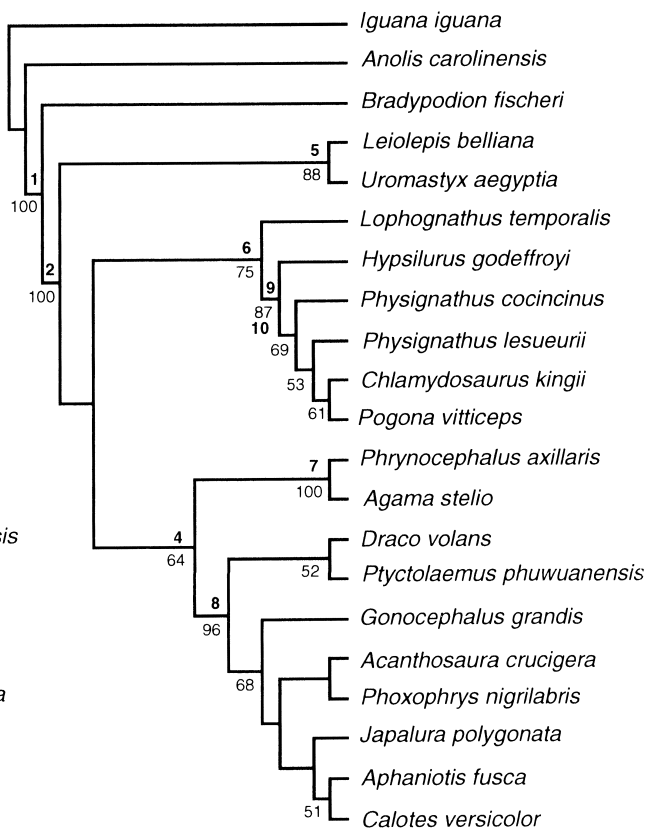

0.1

Fig. 3. (A) Neighbor-joining (NJ) dendrogram deriving from distance matrix from $12 \mathrm{~S}$ and $16 \mathrm{~S}$ rRNA sequence data. Numbers beneath branches are bootstrap proportions (BPs) at least $50 \%$ of the 1,000 bootstrap pseudoreplications. Nodes with bold numbers are identical with ML and MP analyses. Bar equals 0.1 unit of Kimura's (1980) two-parameter distance. (B) Maximum-likelihood (ML) dendrogram (In likelihood =-14358.4). All branches were supported in significantly positive $(\mathrm{P}<1 \%)$. Bar equals 0.1 unit. (C) Maximum parsimony (MP) cladogram using heuristic option (2,202 steps, 443 bp informative under the condition of parsimony, consistency index $=0.41)$. Branches without BP values were not supported in $\geq 50 \%$ of the replicates. 


\section{Phylogenetic relationships}

The $\mathrm{NJ}$ dendrogram derived from aligned sequences is shown in Fig. 3A. Ten nodes (nodes 1-10) were supported with significant BPs. The monophyly of Acrodonta (i.e., agamines, leiolepidines and chameleons) was supported in all bootstrap iterations (node 1: $\mathrm{BP}=100 \%$ ). The ingroup portion of this dendrogram was divided into two major lineages, of which one was monotypic with Bradypodion of the Chamaeleonidae. The other (node 2: $100 \%$ ) contained all genera of the Agamidae examined. These agamid lizards showed a dichotomous relationship. One of the major clusters (node 3: 85\%) further split into two subcluster (nodes $5,6)$. Of these, node $5(93 \%)$ consisted of Leiolepis and Uromastyx (Group I [Moody, 1980] or Leiolepidinae [Frost and Etheridge, 1989]), whereas, node 6 (87\%) accommodated several Australian genera. In the latter, Lophognathus (Group III) was first diverged, followed by the Hypsilurus (Group IV), leaving Physignathus (Group II), Chlamydosaurus (Group III) and Pogona (Group III) as monophyletic (node 10: 96\%). The other major cluster (node 4: $84 \%$ ) split into two subclusters (nodes 7,8$)$. Of these, node $7(100 \%)$ consisted of Phrynocephalus and Agama (Group VI), whereas node 8 (100\%) contained all Group V genera (i.e., Acanthosaura, Aphaniotis, Calotes, Draco, Gonocephalus, Japalura, Phoxophrys and Ptyctolaemus).

Relationships depicted as a result of ML (Fig. 3B) and MP analyses (Fig. 3C) showed no inconsistency with those expressed in the $\mathrm{NJ}$ dendrogram in terms of topology of nodes 1-10, except for the absence of node 3 in MP. In the ML dendrogram, all branches were supported with significant $\mathrm{P}$-values. Likewise, the MP cladogram, though giving no supports to node 3 , showed no conflicts with other two analyses at the level of $B P s \geq 50 \%$.

\section{Comparisons of phylogenetic hypotheses}

The MP cladogram derived from morphological data is shown in Fig. 4. The ingroup portion was divided into two major clusters, of which one, consisting of Leiolepis and Uromastyx (Group I), was supported in $100 \%$ BP. The other major cluster, supported in $97 \%$ BP, contained Groups II-VI. Within the latter, Groups III-VI constituted a cluster (75\%). Monophyly of Group V was also supported (74\%). By contrast, monophyly was not supported with significant BP values for each of the Groups II, III, and IV. As to Group VI, monophyly was rather weakly supported $(66 \%)$.

Independent MP analyses of DNA sequence and morphological data sets yielded different phylogenetic hypotheses (compare Fig. 3C and Fig. 4). When the Templeton's (1983) test was applied to morphological data of 19 OTUs, topology in the MP cladogram was significantly more parsimonious than that from molecular data $(T s=5, n=75)$. When this test was applied to molecular data, the MP cladogram was also significantly shorter than that from morphological data $(T s=44$, $\mathrm{n}=712$ ). The partition homogeneity test revealed a significant heterogeneity between two data sets. These results imply that the molecular and morphological data sets are conflicting.

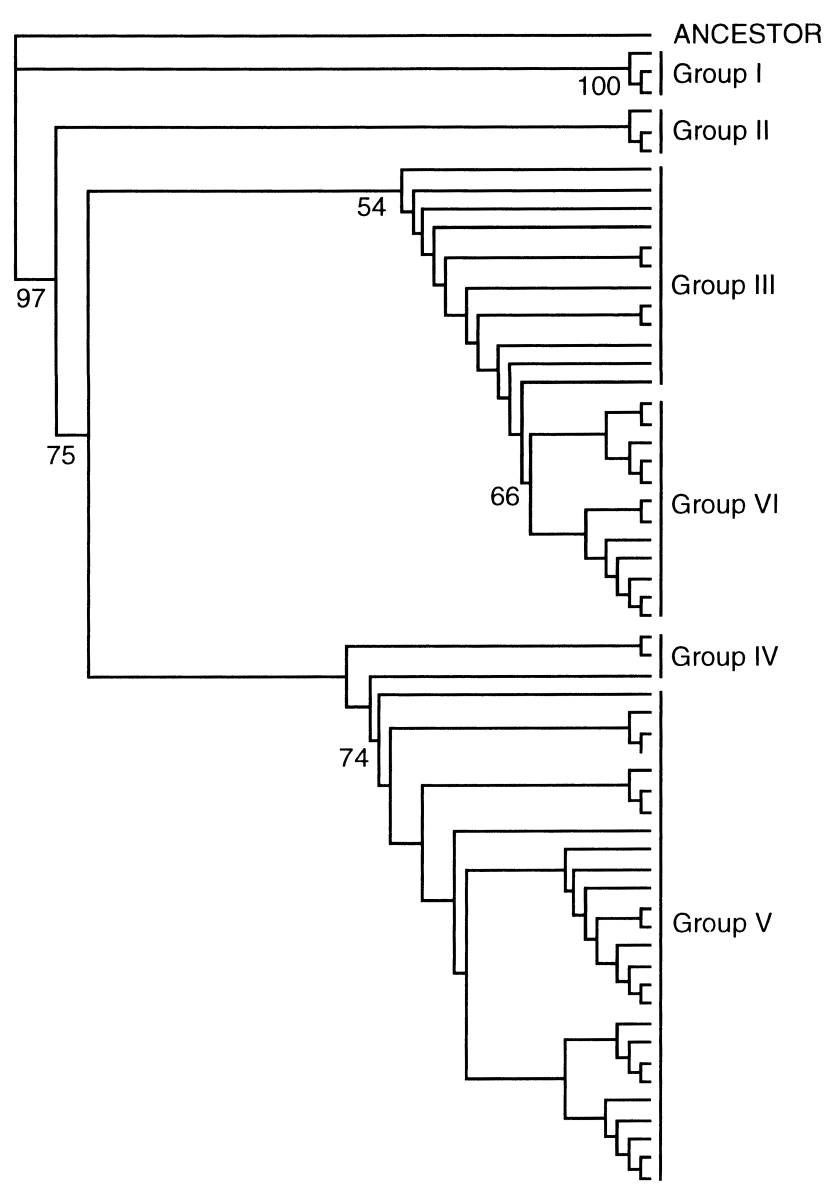

Fig. 4. Strict consensus tree of 48 equally most-parsimonious tress generated from analysis of morphological data provided by Moody (1980) (762 steps, 119 informative under the condition of parsimony, consistency index $=0.23$ ). Branches without $B P$ values were not supported in $\geq 50 \%$ of 1,000 replicates. Species names and intra-group $\mathrm{BP}$ values are omitted.

We thus separately examined data sets phylogenetically in order to avoid a decrease in OTUs in the combined analysis, although the relationships derived from the combined analysis (not given) was largely consistent with the MP analysis of DNA sequence data.

\section{DISCUSSION}

\section{Monophyly of the family Agamidae}

Acrodonta (i.e., agamines, leiolepidines and chameleons) are known to exclusively share a number of morphological features, such as maxillaries in broad contact behind the premaxilla (Moody, 1980; Estes et al., 1988; Frost and Etheridge, 1989). A support to the monophyly of Acrodonta has also been provided from the analyses of data for sequences and the secondary structures in mitochondrial tRNA genes as well (Macey et al., 1997). Our results further confirmed its monophyly and strongly support the validity of those morphological characters as synapomorphs of Acrodonta.

Moody (1980), in his phylogenetic analysis on the basis of morphological data, hypothesized the primary dichotomy 
of Agamidae (sensu lato) into the Leiolepis-Uromastyx clade (Group I) and the remainder (Groups II-VI) (Fig. 1). Thus, Moody (1980, 1983) and Böhme (1982) separated Leiolepis and Uromastyx from the Agamidae (sensu lato), reviving the family Uromastycidae (=subfamily Leiolepidinae: Frost and Etheridge, 1989). Borsuk-Bialynicka and Moody (1984) reduced this group to the subfamilial status. All these authors took an a priori assumption for monophyly of the Agamidae (sensu lato). However, Frost and Etheridge (1989) lumped Agamidae with Chamaeleonidae, and recognized three subfamilies, Agaminae, Leiolepidinae and Chamaeleoninae, in the latter, because their cladistic analysis of morphological data yielded two alternative equally parsimonious relationships: ((Agaminae, Chamealeoninae), Leiolepidinae), and ((Agaminae, Leiolepidinae), Chamealeoninae). Macey et al. (1997), based on the analysis of DNA sequence data of some portions of mitochondrial genes (tRNAs, ND1, ND2 and COI) and those combined with morphological data listed in Frost and Etheridge (1989), indicated the closest relationship between Physignathus and Phrynocephalus (i.e., representatives of Agamidae sensu stricto) within Acrodonta with significant $\mathrm{BP}$ values. They went so far as to even argue that both the Agamidae (sensu lato) and the Leiolepidinae are metataxa, because they failed to support the monophyly of the Agamidae or of leiolepidines (Uromastyx and Leiolepis). By contrast, our analysis of other mitochondrial gene (12S and 16S rRNAs) sequences strongly supported the monophyly of the family Agamidae (against Chamaeleonidae as representative by Bradypodion fischeri) and the sister relationship of Uromastyx and Leiolepis (see further discussion below). With respect to the intergeneric phylogeny, the sequence variation in $12 S$ and 16S rRNA genes may possibly be regarded as being more informative than those in other domains, judging from results of recent studies on other taxa (e.g., Heise et al., 1995; Georges et al., 1999). We thus consider that our results strongly support the validity of the family Agamidae (contra Frost and Etheridge, 1989).

\section{Diversification of Agamidae}

Among the results of analyses of morphological data by Moody (1980) using unweighted and weighted Wagner tree algorithms, and compatibility methods, phylogenetic relationships were rather unstable, and only five branching topologies were consistently supported: (1) the dichotomy between the Group I and the Groups II-VI; (2) the monophyly of the members of the Groups III-VI; (3) the monophyly of the members of the Groups V-VI; (4) the monophyly of the Group III; and (5) the monophyly of the Group VI. Our analysis of his data with bootstrap resamplings (Felsenstein, 1985) resolved only (1), (2) and the monophyly of the Group V with significant BPs (Fig. 4). This may suggest that the agamid lizards have few phylogenetically informative morphological characters. By contrast, our approach using the molecular data seems to be much more useful in resolving the relationships of agamids, indicating a large dichotomy between a relatively primitive group including Australian and Melanesian members (Groups
I-IV), and a more advanced group (Groups V-VI).

Joger (1991), on the basis of immunological data, argued for the monophyly of the Group VI. His results, however, failed to support the monophyly of the Group I, the Groups II-IV complex, or the Group V. Our results strongly suggest the monophyly of each of the latter three groups as well. We suspect that Joger's (1991) analysis suffered partially because of the limited resolving power of immuno-distance data as a result of more or less subjective estimate of the intensity of precipitin arcs (Greer, 1986), and also because of the insufficient number of samples from the "non-Group VI" members.

Although Uromastyx has been occasionally referred to as a typical agamid (Camp, 1923; Jollie, 1960), it also has a few highly specialized morphological features (Moody, 1980). Some authors (e.g., Moody, 1980, 1983; Borsuk-Bialynicka and Moody; Frost and Etheridge, 1989) thus classified this genus, together with its putative closest relative Leiolepis, to an independent family or subfamily. Nevertheless, analysis of sequence data for mitochondrial tRNAs, ND1, ND2 and COI genes did not support the dichotomy of the LeiolepisUromastyx clade and the remainder (Macey et al., 1997). Our results of $\mathrm{NJ}$ and $\mathrm{ML}$ analyses of data for mitochondrial $12 \mathrm{~S}$ and 16S rRNA gene sequences did not support the validity of the subfamily Leiolepidinae or family Uromastycidae, either, because, although the two genera constituted a well supported clade (contra Macey et al., 1997), they did not show a sister relationship with all remaining agamids. MP analysis yielded no substantial account with respect to this problem. We thus consider any taxonomic separation of Leiolepis and Uromastyx from the remainder as inappropriate.

Members of the Group II are morphologically relatively primitive and are characterized by herbivory (e.g., Moody, 1980). In a different group of Iguania, primitive members are reported to constitute basal branches in a phylogenetic tree (Frost and Etheridge, 1989). Contrary to such a pattern, phylogenetic relationships inferred from DNA sequence in the present study do not support the early divergence of the primitive Group II, and suggest its possible non-monophyly. This is surprising especially when considering that both of the two taxa representing the Group II in our analyses are currently assigned to a single genus (Physignathus). It is thus probable that the morphological and ecological similarities among the Group II members actually represent symplesiomorphy or convergence. Further analyses are strongly desired to revise the generic arrangement of the two species examined here.

Lophognathus (Group III), occasionally regarded as synonymous with Physignathus (Wermuth, 1967; Matsui, 1992), was distantly located from either of the two Physignathus species within the Australian radiation (Fig. 3). This seems to support the validity of Lophognathus (e.g., Moody, 1980; Cogger, 1994). The morphological similarities between this genus and the two species of Physignathus may reflect symplesiomorphy or convergence, too.

Moody (1980) assumed the monophyly of Group III, and attributed its diversity to the Australian in situ radiation. Our results, while supporting the Australian origin of its diversity 
(see below), negate the monophyly of the Group III.

In our analysis of Moody's (1980) morphological data, the monophyly of the Groups V and VI was not supported at all (Fig. 4). By contrast, our molecular analyses strongly suggested the sister relationship of these two monophyletic groups. Considering the closest associations of the arboreal Group V with the likewise arboreal Group IV, and of the terrestrial Group VI with the largely terrestrial Group III in Fig. 4, we suspect that the results of the former analysis is influenced by the convergent characters independently evolved in response to similar ecological requirements. Our molecular analyses, on the other hand, failed to elucidate relationships within the Group $\mathrm{V}$ in detail. This may reflect the almost concurrent radiation of all lineages of this group examined here.

\section{Biogeography of Agamidae}

It is noteworthy that node 6 in our phylogenetic relationships (Fig. 3) exclusively consists of Australian agamids except for the Southeast Asian Physignathus cocincinus. Some authors argued that the ancestors of at least a part of the agamid fauna of Australian region (including Papua New Guinea and adjacent islands) have entered this continent from Eurasia through the Sunda Islands, a fringing archipelago between Malay Peninsula and New Guinea (e.g., Hecht, 1975; Tyler, 1979; Cogger and Heatwole, 1981; Witten, 1982, 1983). Others claimed that almost all agamids were derived from the Australian endemic radiation, and that they have no direct relationships with the tropical Asian agamids (e.g., Baverstock and Donnellan, 1990; King, 1990). Witten (1982, 1983), on the basis of morphological and karyological features, divided the Australian agamids into two groups. He assumed members of the smaller group, including Physignathus (Group II) and Hypsilurus (Group IV, referred to as Gonocephalus at that date: see below), as recent derivatives from the Asian stock, and the others as originating from an old endemic radiation in Australia. Moody (1980), while postulating the Australian endemic radiation for the Group III, supposed that the agamid fauna of this region increased through multiple colonizations from Southeast Asia. However, according to the phylogenetic relationships inferred above, the Australian endemic members (Groups II-IV) seem to have been derived entirely through an in situ radiation. Distribution of Physignathus cocincinus is thus considered as a consequence of the secondary dispersal. Occurrence of Hypsilurus in Melanesia also seems to represent a colonization from Australia. Such a process contrasts with that for the diversification of Australian varanids, because the current diversity of this gigantic lizard family in the Australian region is considered to have increased through multiple colonizations from Asia on the basis of DNA sequence data (Fuller et al., 1998).

Darlington (1957) highlighted the zoogeographically characteristic distribution of the genus Gonocephalus (sensu lato), which occurs across the Wallacia, a border of the Oriental and Australian faunal realms. However, Moody (1980), on the basis of morphological data, argued for the distant affinity between the species occurring in the west and east of Wallacia, and insisted on the validity of Hypsilurus, a nominate genus synonymized of Gonocephalus at that date, to accommodate the latter species. Witten (1983), however, pointed out that the number of micro-chromosomes in Gonocephalus (or Hypsilurus) spinipes from the Australian region is equivalent to those in several Asian species, and is greater than those in most other Australian agamids. He regarded such a similarity pattern as indicative of a closer phylogenetic affinity of this species with Asian agamids. Based on the immunological data, Baverstock and Donnellan (1990), and King (1990) supported Moody's (1980) view and considered "Gonocephalus" east of Wallacia as a part of the post Gondwanaland endemic Australian radiation. Furthermore, Ota et al. (1992) also indicated distinct chromosomal differences between Gonocephalus grandis and G. miotypanum from Southeast Asia, and "G". spinipes. Our results, demonstrating a much closer phylogenetic affinity of Hypsilurus with other Australian agamids than with the Southeast Asian Gonocephalus, further support the latter view.

As contrasted with the agamid fauna of the Australian region, that of the Asian and African region consists of two distinct components - the Leiolepis-Uromastyx clade (node 5 ), and the other Asian-African agamids (node 4). Leiolepis and Uromastyx, although phylogenetically closest to each other, are geographically greatly isolated in Southeast Asia, and West Asia and Africa, respectively. This strongly suggests the relict nature of these genera.

The Groups V (node 8) and VI (node 7), while being monophyletic to each other (node 4), differ from each other geographically (distributed in South-Southeast Asia, and central-West Asia and Africa, respectively: Moody, 1980; Matsui, 1992). Judging from the fact that the current diversity of the Group VI is centered in West Asia and Africa (Moody, 1980; Matsui, 1992), it is likely that this group and the Group V diverged trough the vicariance between West Asia and South Asia, and that the central Asian representatives of the Group VI (a few species of Phrynocephalus) were derived from the secondary dispersal.

Cracraft (1974) divided the all modern groups of lizards into northern (Laurasian) and southern (Gondwanan) elements, and placed the Agamidae in the latter. However, present results do not support the Gondwanaland origin of the Agamidae, because they failed to demonstrate secondary derivations of the Laurasian (i.e., Asian) agamids from the Gondwanan (i.e., African and Australian) relatives. On the other hand, fossil evidence suggests the East Asian origin of the Agamidae (Borsuk-Bialynicka and Moody, 1984). Thus, it is more likely that the common ancestor of the family emerged in Asia, and that African and Australian agamids were originated through the secondary dispersals from Asia. This view is circumstantially supported by the highest species diversity in Southeast Asia, and by the absence of the agamid lizards in other Gondwanan areas such as Madagascar and South America. 


\section{ACKNOWLEDGMENTS}

We would like to thank M. Matsui, T. Hidaka, S. Panha, M. Ishii, M. Kon, K. Araya, A. Mori, K. Otsuka, S. Furukawa, T. Hayashi, M. Toda, I. Miyagi, T. Toma, H. Hasegawa, A. Miyata, T. Chan-Ard, R. Goh, R. F. Goh, L. Saikeh, V. Chey, L. David, A. A. Hamid, C. J. Chong, S. Cheng, the staff of the entomological section of the Forest Research Center, Sepilok, the staff of National Park and Wildlife and Forest Research Sections, Forest Department of Sarawak, and the staff of Hasanuddin University at Ujun Pandang, for providing us with various helps and encouragements during our fieldwork. We are also much indebted to $\mathrm{H}$. Nagaoka, A. Suzuki and Y. Yasukawa for providing specimens, to $\mathrm{M}$. Katoh for literature, and to N. Nikoh for helps with phylogenetic analyses. Special thanks are due N. Satoh and members of his laboratory for continuous support for our laboratory experiments. Experiments were also carried out using the facilities of the Kyoto University Museum.

Honda, Ota and Hikida are especially grateful to T. Hidaka, M. Matsui and I. Miyagi for providing opportunities to visit Malaysia, Thailand and Indonesia. Our research was partially supported by Grantsin-Aid from the Japan Ministry of Education, Science, Sports and Culture (Overseas Researches Nos. 404326, 60041037, 61043033, 62041049, 63043037, 01041051, 02041051 and 03041044 to $T$. Hidaka, 04041068,06041066 and 18041144 to M. Matsui, and 03041065 to I. Miyagi; Basic Researches C-11833013 to H. Ota and C-10836010 to T. Hikida), and the Nakayama Foundation for Human Science.

\section{REFERENCES}

Avery RA (1982) Field studies of body temperatures and thermoregulation. In "Biology of the Reptilia Vol.12, Physiology C" Eds by C Gans, FH Pough, Acad Press, London, pp 93-166

Baverstock PB, Donnellan SC (1990) Molecular evolution in Australian dragons and skinks: a progress report. Mem Queensland Mus 29: 323-331

Böhme W (1982) Über Schmetterlingsagmen, Leiolepis b. belliana (Grey, 1827) der Malayischen Halbinsel und ihre parthenogenetischen Linien (Sauria: Uromastycidae). Zool J Syst 109: 157-169

Borsuk-Bialynicka M, Moody SM (1984) Priscagaminae, a new subfamily of the Agamidae (Sauria) from the late Cretaceous of the Gobi desert. Acta Palaeont Polonica 9: 51-81

Brown WM, Prager EM, Wang A, Wilson AC (1982) Mitochondrial DNA sequence of primates: tempo and mode of evolution. $J$ Mol Evol 18: 225-239

Camp CL (1923) Classification of the lizards. Bull Amer Mus Nat Hist 48: $289-481$

Cogger HG (1994) Reptiles and Amphibians of Australia, 5th ed. Cornell Univ Press, New York

Cogger HG, Heatwole H (1981) The Australian reptiles: origins, biogeography, distribution patterns and island evolution. In "Ecological Biogeography of Australia" Ed by A Keast, W Junk Publ, Hague

Cracraft J (1974) Continental drift and vertebrate distribution. Ann Rev Ecol Syst 5: 215-261

Darlington PJJr (1957) Zoogeography: The Geographical Distributions of Animals. John Wiley, New York

Estbrook GF, Strauch JG, Fiala KL (1977) An application of compatibility analysis to Blackiths' data on orthopteroid insect. Syst Zool 26: $269-276$

Estes R, de Queiroz K, Gauthier J (1988) Phylogenetic relationship within Squamata. In "Phylogenetic Relationships of the Lizard Families" Eds by R Estes, G Pregill, Stanford Univ Press, Stanford, pp 119-281

Farris, JS (1969) A successive approximations approach to character weighting. Syst Zool 18: 374-385
Farris, JS (1970) Methods for computing Wagner trees. Syst Zool 19: 172-189

Farris JS, Källersjö M, Kluge AG, Bult C (1994) Testing significance of incongruence. Cladistics 10: 315-319

Felsenstein J (1985) Confidence limits on phylogenies: an approach using the bootstrap. Evolution 39: 783-791.

Felsenstein J, Kishino H (1993) Is there something wrong with the bootstrap on phylogeny? A reply to Hillis and Bull. Syst Biol 42: 193-200.

Frost DR, Etheridge R (1989) A phylogenetic analysis and taxonomy of iguanian lizards. Pub Univ Kansas 81: 1-65

Fuller S, Baverstock PB, King D (1998) Biogeographic origins of goannas (Varanidae): a molecular perspective. Mol Phyl Evol 9: 294-307

Greer AE (1986) Lygosomine (Scincidae) monophyly: a third, corroborating character and a reply to critics. J Herpetol 20: 123126

Georges A, Birrell J, Saint KM, McCord W, Donnellan, SC (1999) A phylogeny for side-necked turtles (Chelonia: Pleurodia) based on mitochondrial and nuclear gene sequence variation. Biol $\mathrm{J}$ Linn Soc 67: 213-246

Gilbert D (1993) SeqApp Manual Aligner for Macintosh, Ver. 1. Indiana Univ, Bloomington

Hecht M (1975) The morphology and relationships of the largest known terrestrial lizard, Megalania prisca Owen, from the Pleistocene of Australia. Proc Royal Soc Victoria 87: 239-250

Hedges SB, Bezy RL, Maxson LR (1991) Phylogenetic relationships and biogeography of Xantusiid lizards inferred from mitochondrial DNA sequences. Mol Biol Evol 8: 767-780

Hedges SB, Nussbaum RA, Maxson LR (1993) Caecilian phylogeny and biogeography inferred from mitochondrial DNA sequences of the 12S rRNA and 16S rRNA genes (Amphibia: Gymnophiona). Herpetol Monogr 7: 64-76

Heise PJ, Maxson LR, Dowling HG, Hedges SB (1995) Higher-level snake phylogeny inferred from mitochondrial DNA sequences of 12S rRNA and 16S rRNA genes. Mol Biol Evol 12: 259-265

Hillis DM, Bull JJ (1993) An empirical test of bootstrapping as a method for assessing confidence in phylogenetic analysis. Syst Biol 42 : $182-192$

Honda M, Ota H, Kobayashi M, Nabhitabhata J, Yong H-S, Hikida T (1999a) Phylogenetic relationships of the flying lizards, genus Draco (Reptilia, Agamidae). Zool Sci 16: 535-549

Honda M, Ota H, Kobayashi M, Nabhitabhata J, Yong H-S, Hikida T (1999b) Evolution of Asian and African lygosomine skinks of the Mabuya group (Reptilia: Scincidae): a molecular perspective. Zool Sci 16: 979-984

Joger U (1991) A molecular phylogeny of Agamid lizards. Copeia 1991: $616-622$

Jollie MT (1960) The head skeleton of the lizard. Acta Zool 61: 1-64

Kimura M (1980) A simple method for estimating evolutionary rate of base substitutions through comparative studies of nucleotide sequences. J Mol Evol 16: 116-120

King M (1990) Chromosomal and immunogenetic data: a new respective on the origin of Australia's reptile. In "Cytogenetics of Amphibians and Reptiles" Ed by E Olmo, Birkhauser Verlag, Basel, pp 153-180

Kocher TD, Thomas WK, Meyer A, Edwards SV, Pääbo S, Villablanca FX, Wilson AC (1989) Dynamics of mitochondrial DNA evolution in animals: Amplifications and sequencing with conserved primers. Proc Nat Acad Sci USA 86: 189-191

Kupriyanova LA (1984) Karyotypes of three species of the agamid lizards. In "Ecology and Faunistics of Amphibians and Reptiles of the USSR and Adjacent Countries" Ed by LJ Borkin, Zool Inst Acad Sci, Leningrad, pp 115-118 (in Russian with English summary)

Lazell J (1992) The family Iguanidae: Disagreement with Frost and Etheridge (1989). Herpetol Rev 23: 109-112 
Macey JR, Larson A, Ananjeva NB, Papenfuss TJ (1997) Evolutionary shifts in three major structural features of the mitochondrial genome among iguanian lizards. J Mol Evol 44: 660-674

Maddison WP and Maddison DR (1992) MacClade: Analysis of Phylogeny and Character Evolution, version 3.0. Sinauer Associates, Massachusetts

Matsui M (1992) Systematic Zoology, Vol. 9. Vertebrate Ilb2, Reptilia. Nakayama Shoten, Tokyo (in Japanese)

Moody SM (1980) Phylogenetic and historical biogeographical relationships of the genera in family Agamidae (Reptilia: Lacertilia). Unpubl PhD Thesis, Univ Michigan, Michigan

Moody SM (1983) The rectos abdominis muscle complex of the Lacertilia: terminology, homology, and assumed presence in primitive iguanian lizards. In "Advances in Herpetology and Evolutionary Biology" Eds by AGJ Rhodin, K Miyata, Cambridge, Massachusetts

Moody SM, Hutterer HR (1978) Karyotypes of the agamid lizard Lyriocephalus scutatus (L, 1758), with a brief review of the chromosomes of the lizard family Agamidae. Bönn Zool Beitr 29: 165170

Mori A, Hikida T (1993) Natural history observation of the flying lizard, Draco volans sumatranus from Sarawak, Malaysia. Raffles Bull Zool 41: 83-94

Olsen GJ, Matsuda H, Hagstorm H, Overbeek R (1993) fastDNAml: a tool for constructions of phylogenetic trees of DNA sequences using maximum likelihood. Comp Appl Biosci 10: 41-48

Ota $\mathrm{H}$ (1988) Karyotypic differentiation in an agamid lizard, Japalura swinhonis swinhonis. Experientia 44: 66-68

Ota H (1989a) Japalura brevipes Gressitt (Agamidae: Reptilia), a valid species from a high altitude area of Taiwan. Herpetologica 45: $55-60$

Ota H (1989b) A new species of Japalura (Agamidae: Lacertilia: Reptilia) from Taiwan. Copeia 1989: 569-576

Ota H, Hikida T (1989) Karyotypes of three species of the genus Draco (Agamidae: Lacertilia) from Sabah, Malaysia. Jpn J Herpetol 13: $1-6$

Ota H, Honda M, Kobayashi M, Sengoku S, Hikida T (1999) Phylogenetic relationships of Eublepharid geckos (Reptilia: Squamata): a molecular approach. Zool Sci 16: 659-666

Ota H, Matsui M, Hikida H, Mori A (1992) Extreme karyotypic divergence between species of the genus Gonochephalus (Reptilia: Squamata: Agamidae) from Borneo and Australia. Herpetologica 48: $120-124$

Rieppel O (1981) The skull and jaw adductor musculature in chamaeleons. Rev Suisse Zool 88: 433-445

Saiki RK, Gelfand DH, Stoffel S, Scharf SJ, Higuchi R, Horn GT, Mullis KB, Ehrlich HA (1988) Primer-directed enzymatic amplification of DNA with a thermostable DNA polymerase. Science 239: 487491
Saitou N, Nei M (1987) The neighbor-joining method: a new method for reconstructing phylogenetic trees. Mol Biol Evol 4: 406-425

Schwenk K (1994) Systematics and Subjectivity: The Phylogeny and classification of iguanian lizards revisited. Herpetol Rev 25: 5357

Shaffer HB, Meylan P, McKnight ML (1997) Tests of turtle phylogeny: molecular, morphological, and paleontological approaches. Syst Biol 46: 235-268

Sokolovsky VV (1974) A comparative karyological study of the lizards of the family Agamidae I. Chromosome complements of 8 species of the genus Phrynocephalus (Reptilia, Agamidae). Tsitologiya 16: 920-925

Stamps JA (1977) Social behavior and spacing patterns in lizards. In "Biology of the Reptilia, Vol.7, Ecology and Behavior A" Eds by C Gans, DW Tinkle, Acad Press, London, pp 256-334

Swofford DL (1998) A Phylogenetic Analysis Using Parsimony ("and Other Method) ver 4.0. Massachusetts

Templeton, A (1983) Phylogenetic inference from restrction endonuclease clavage site maps with particular reference to the evolution of humans and apes. Evolution 37: 221-244

Thomas RH, Schaffner W, Wilson AC, Pääbo S (1989) DNA phylogeny of the extinct marsupial wolf. Nature 340: 465-467

Thompson JD, Higgins G, Gibson TJ (1994) CLUSTAL W: improving the sensitivity of progressive multiple sequence alignment through sequence weighting, position specific gap penalties and weight matrix choice. Nucl Acids Res 22: 4673-4680

Titus TA, Frost DR (1996) Molecular homology assessment and phylogeny in the lizard family Opluidae (Squamata: Iguana). Mol Phyl Evol 6: 49-62

Tyler MJ (1979) Herpetolofaunal relationships of South America with Australia. In "The South American Herpetofauna, a Symposium. Monograph of Museum of Natural History No.7" Ed by WE Duellman. Univ Kansas, Kansas, pp 73-106

Wermuth GJ (1967) Liste der rezenten Amphibien und Reptilien. Agamidae. Das Tierreich. Walter de Gruyter, Berlin

Witten GJ (1982) Phyletic groups within the family Agamidae (Reptilia: Lacertilia) in Australia. Greenslade In "Evolution of the Flora and Fauna of Arid Australia" Eds by WR Barker, PJM Greenslade, Peacock Book, South Australia

Witten GJ (1983) Some karyotypes of Australian agamids (Reptilia: Lacertilia). Aust J Zool 31: 533-540

Zhang D-X, Hewitt GM (1996) Nuclear integrations: Challenges for mitochondrial DNA markers. Trends Ecol Evol 11: 247-251

(Received August 19, 1999 / Accepted November 12, 1999)

\section{APPENDIX 1}

Localities and catalogue numbers of specimens examined in this study. The specimens were deposited in the herpetological collection of the Department of Zoology, Kyoto University (KUZ). DDBJ accession numbers of 12S and 16S rRNAs are presented in parentheses, respectively. ${ }^{*}$ Imported by a pet dealer (detailed localities unknown). ${ }^{* *}$ Bought in a market (detailed localities unknown). ${ }^{* *}$ Deposited in the herpetological collection of National Science Museum of Thailand .

Acanthosaura crucigera: Ko Chang Is., Thailand, KUZ 35536. Agama stelio: West Asia or North Africa*, 46928. Aphaniotis fusca: Mimaland, Peninsular Malaysia, 22062 (AB023749, AB023771). Calotes versicolor: Ko Chang Is., Thailand, 35570. Chlamydosaurus kingii: Australina*, 46725. Draco volans volans: Borobudur, Java, 38831 (AB023748, AB023770). Gonocephalus grandis: Cameron highland, Peninsular Malaysia, 21436. Hypsilurus godeffroyi: Irian Jaya, New Guinea, 45216. Japalura polygonata polygonata: Ryukyu Is., Japan, 38842. Leiolepis belliana: Thailand $^{\star \star}, 27592$. Lophognathus temporalis: New Guinea*, 46723. Phoxophrys nigrilabris: Matang, Borneo, 27204. Phrynocephalus axillaris: West Asia*, 46726. Physignathus cocincinus: Ko Chang, Thailand ${ }^{* *}$. Physignathus lesueurii: New Guinea*, 45194. Pogona vitticeps: Australina* 45915. Ptyctolaemus phuwuanensis: Phu Wua, Thailand, 40355 (AB023750, AB023772). Uromastyx aegyptia: West Asia or North Africa*, 45913. Bradypodion fischeri: Africa* 45920. Anolis carolinensis: Ogasawara Islands, Japan, 46727. Iguana iguana: America*, 37209 (AB028742, AB028756). 


\section{APPENDIX 2}

Aligned sequences of a 860 bp segment of the 12S and 16S rRNA genes. The initial $393 \mathrm{bp}$ in each row correspond to the $12 \mathrm{~S}$ rRNA gene sequence. The 16S rRNA gene sequence begins at the asterisk. Dot indicates an identity with the first sequence; dash denotes a gap. " $P$." denotes Physignathus. Sharp and plus beneath sequences indicate a gap site and an invariable site, respectively.

Iguana
Anol is
Bradypodion
Acanthosaura
Agama
Aphaniotis
Calotes
Chlamydosaurus
Draco
Gonocephalus
Hypsilurus
Japalura
Leiolepis
Lophognathus
Phoxophrys
Phrynocephalus
P. cocincinus
P. lesueuri i
Pogona
Ptyctolaemus
Uromastyx

Iguana

Anolis

Bradypodion

Acanthosaura

Agama

Aphaniotis

Calotes

Chlamydosaurus

Draco

Gonocephalus

Hypsilurus

Japalura

Leiolepis

Lophognathus

Phoxophrys

Phrynocephalus

$P$. cocincinus

P. lesueuri i

Pogona

Ptyctolaemus

Uromastyx

Iguana

Anolis

Bradypodion

Acanthosaura

Agama

Aphaniotis

Calotes

Chlamydosaurus

Draco

Gonocephalus

Hypsilurus

Japalura

Leiolepis

Lophognathus

Phoxophrys

Phrynocephalus

P. cocincinus

$P$. Lesueuri i

Pogona

Ptyctolaemus

Uromastyx

GCTTAGACGTTAACA-CGACACCCCTCCCACATCGGTGTTCGCCAGAGAAATACTAGCGAAAA-GCTTAAAACTCAAAGGACTTGGCGGTGCTCCAC-CCCGACTTAGAGGAGCCTGTCCTAT-AATCGATAATCCACGATAAACCTTAC

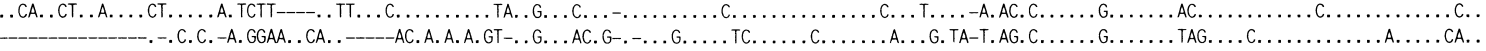

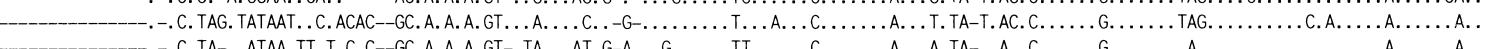

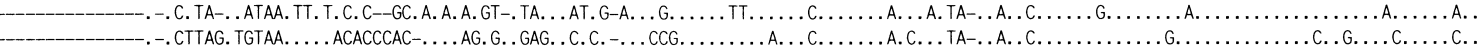

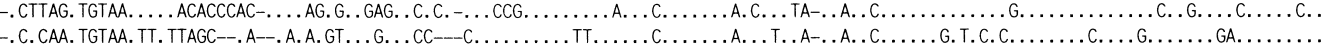

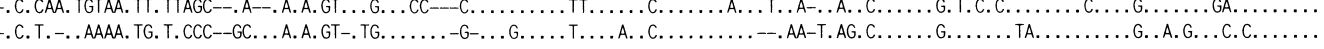

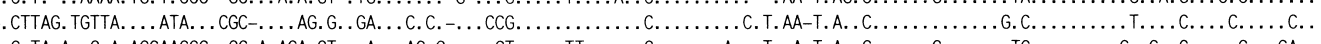

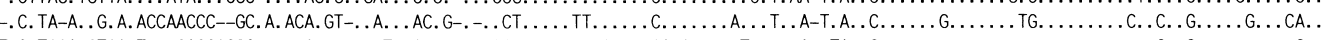

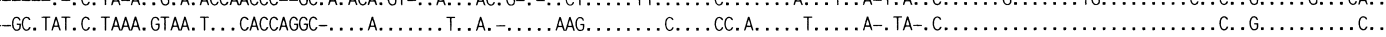

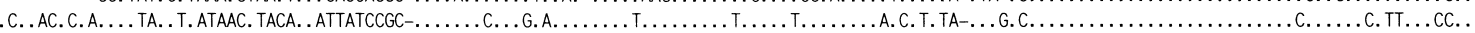

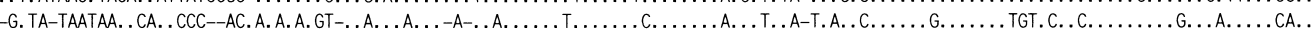

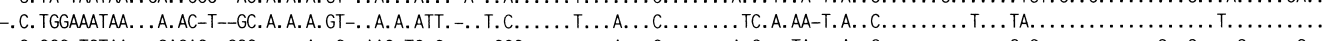

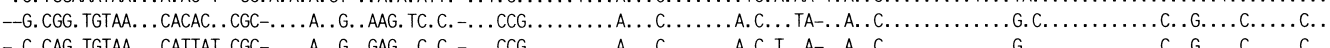

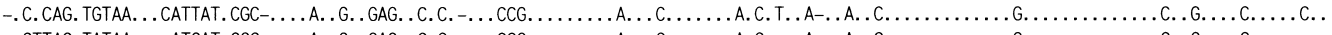

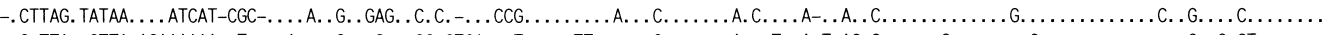

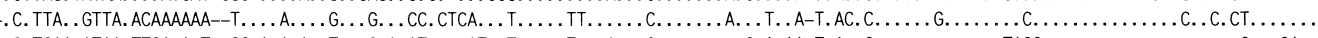

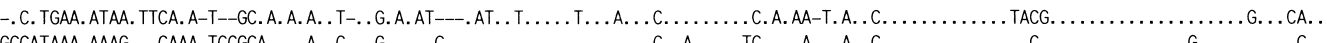

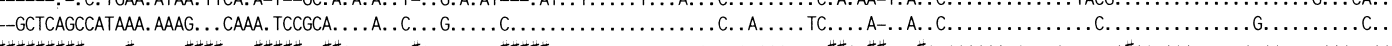

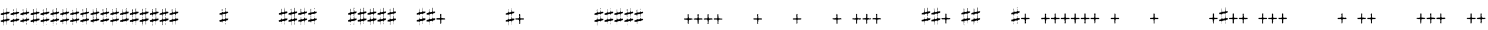

CATTTTTTGCCACATC-_-AGCCTATATACCGCCGTCACCAACTTACCCCATGAGGGCCCAAAAGTAAGTACAACAGTTTAACAACTAAAACGTCAGGTCAAGGTGTAGCTAATAAAATGG-AAGCGATGGGCTACATTTTTTAATATAA

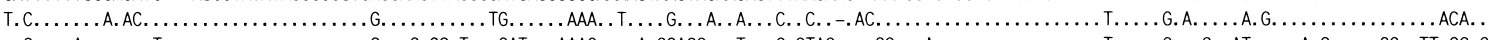

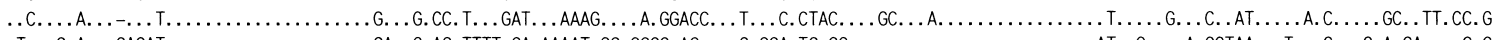

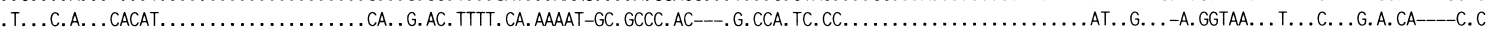

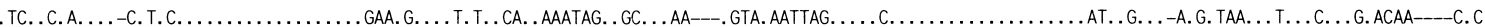

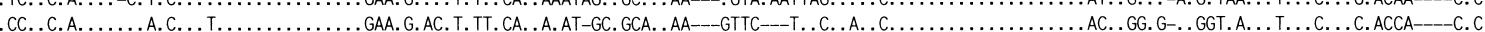

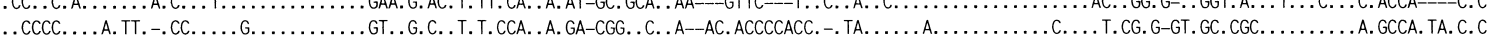

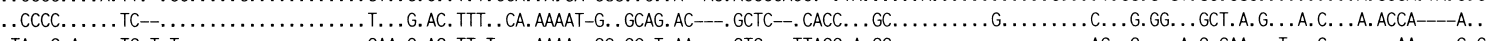

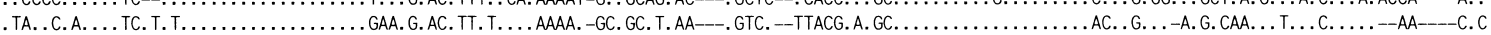

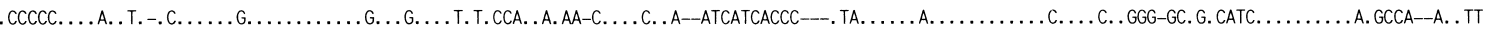

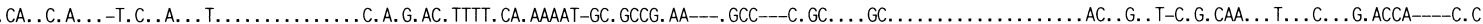

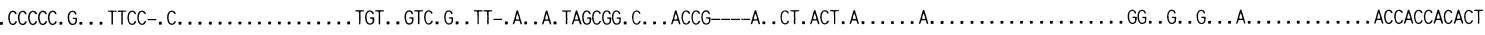

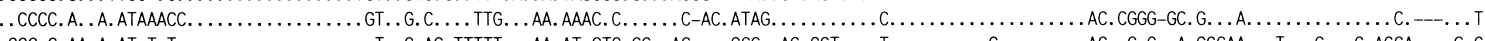

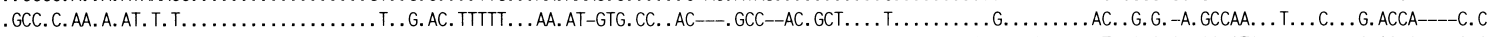

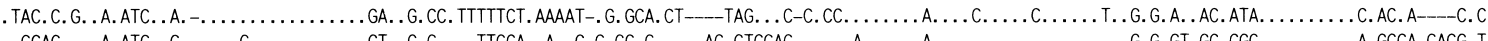

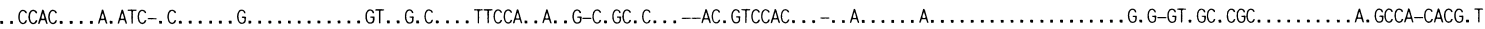

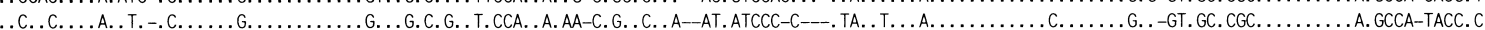

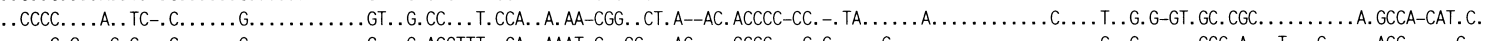

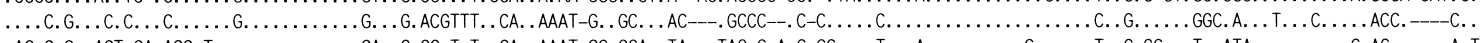

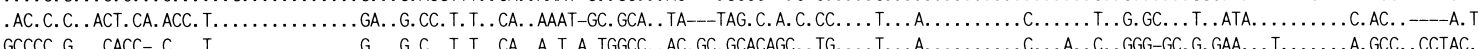

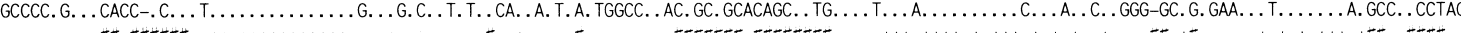

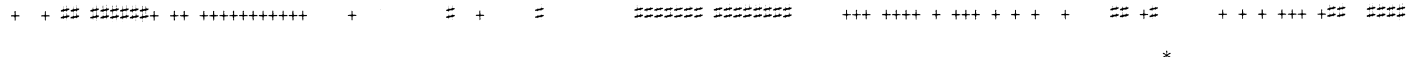

301

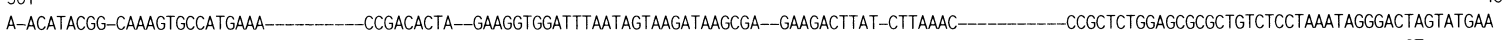

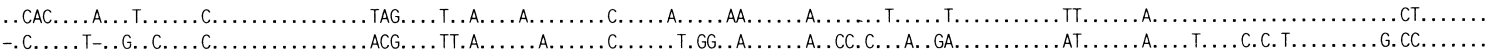

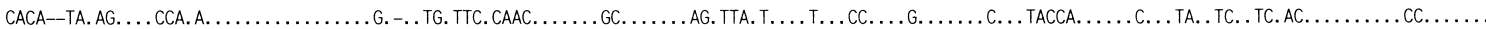

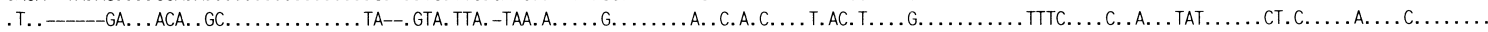
CA. A--. A--. -T. . ACATG. -A. . C. . . . . . . . AC-T. AC. A. -

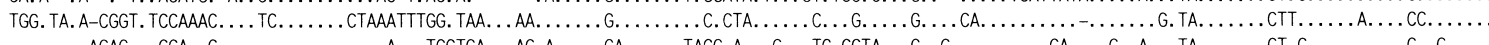

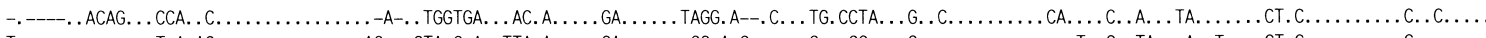

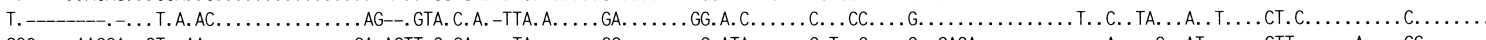

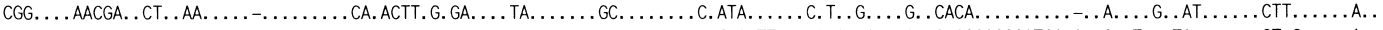

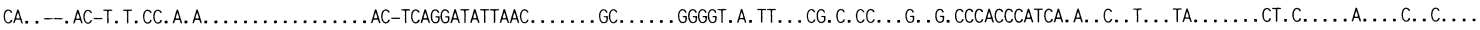

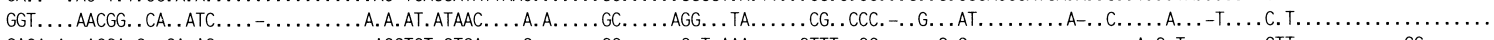

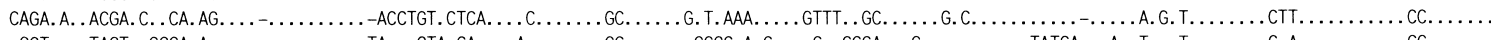

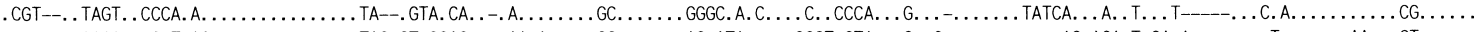

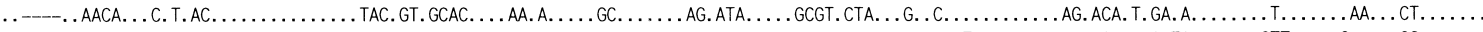

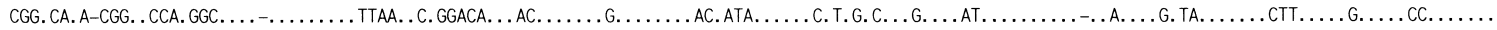

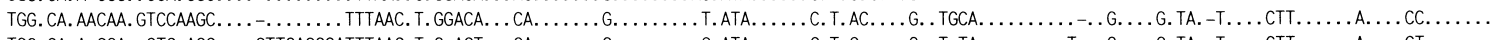

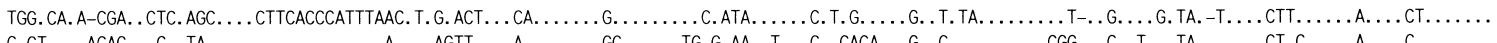

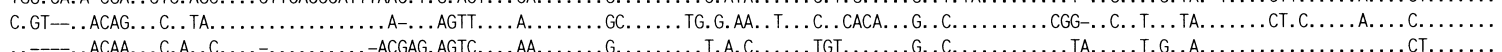

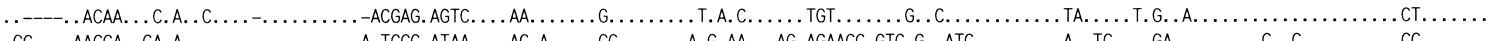

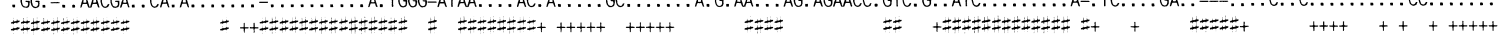


Iguana

Anol is

Bradypodion

Acanthosaura

Agama

Aphaniotis

Calotes

Chlamydosaurus

Draco

Gonocephalus

Hypsilurus

Japalura

Leiolepis

Lophognathus

Phoxophrys

Phrynocephalus

P. cocincinus

P. lesueurit

Pogona

Ptyctolaemus

Uromastyx

Iguana

Anol is

Bradypodion

Acanthosaura

Agama

Aphaniotis

Calotes

Chlamydosaurus

Draco

Gonocephalus

Hypsilurus

Japalura

Leiolepis

Lophognathus

Phoxophrys

Phrynocephalus

P. cocincinus

P. lesueuriti

Pogona

Ptyctolaemus

Uromastyx

\section{Iguana}

Anol is

Bradypodion

Acanthosaura

Agama

Aphaniotis

Calotes

Chlamydosaurus

Draco

Gonocephalus

Hypsilurus

Japalura

Leiolepis

Lophognathus

Phoxophrys

Phrynocephalus

P. cocincinus

P. lesueurit

Pogona

Ptyctolaemus

Uromastyx
451

CGGCTAAACGAGGGTTAACCTGTCTCCTTAGACCAATCAGTGAAA-CTGATCTGCCAGTACAAAAGCTGACATAGCAACATAAGACGAGAAGACCCTGTGGAGCTTTAGACTGACAGCCAAACCAAAACCACCCCACCTCACCCCATGGC

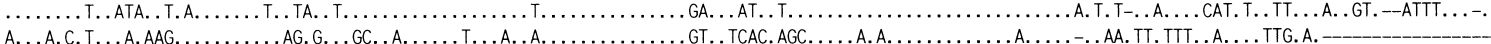

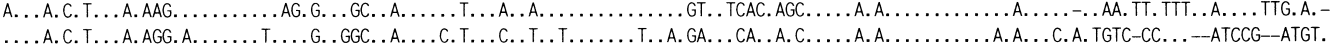

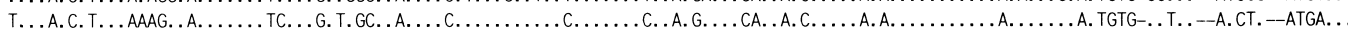

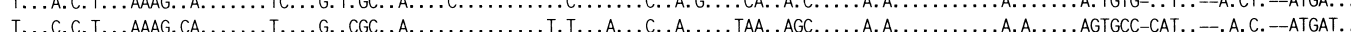

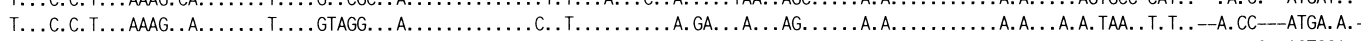

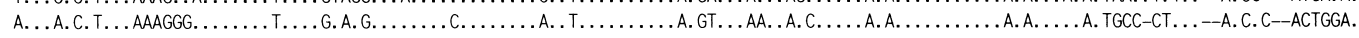

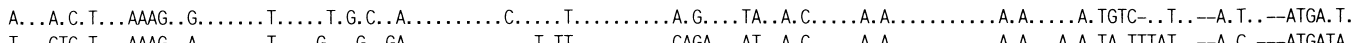

T...CTC. T...AAAG..A.

T...C.C. T...AAAGG.A. ......

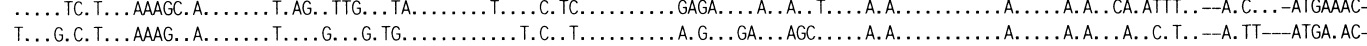

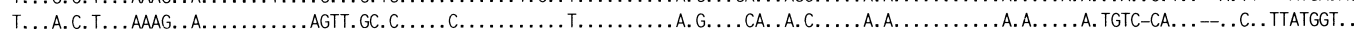

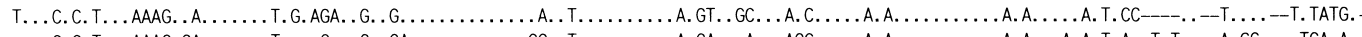

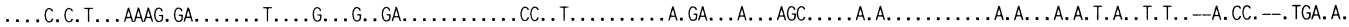

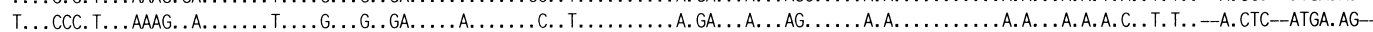

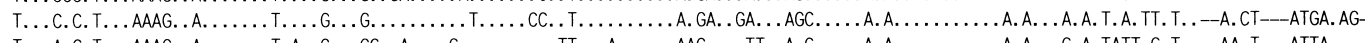

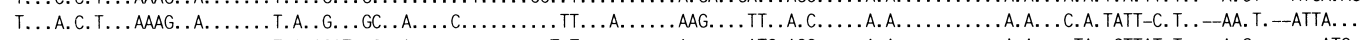

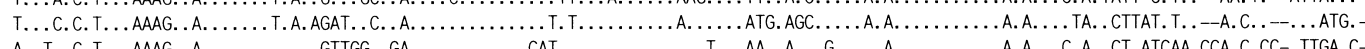

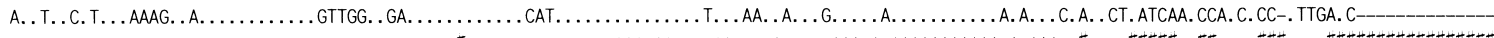

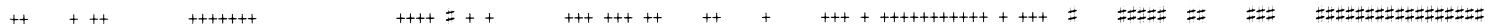

601

TAAAAGTCTTA-AGTTGGGGCGACTTCGGAGCAAAACAAAACCTCCAAGCAACAGAACATCCATCTTCCCTAAGGCAAACACGCCAAAGCAAACAACAGACCCAGTACCACTGACCATCGAACCAAGTTACCCCAGGGATAACAGCGCTA

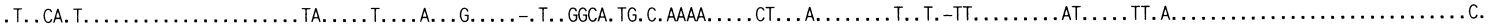

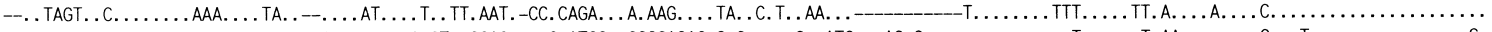

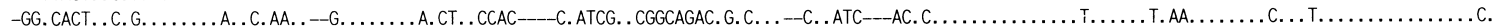

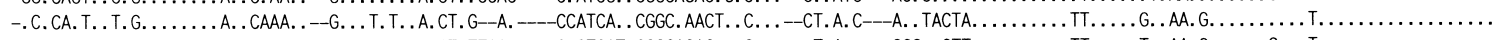

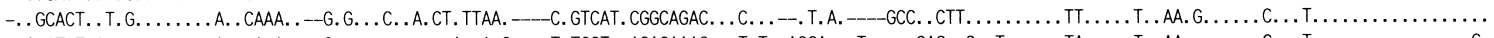

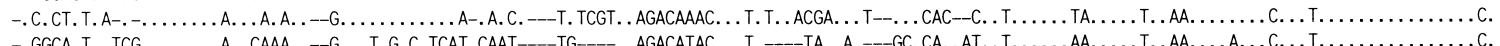

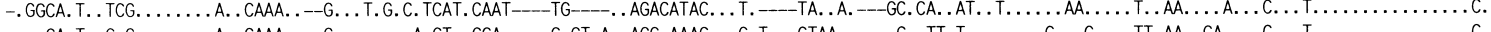

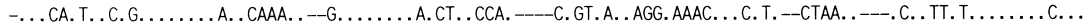

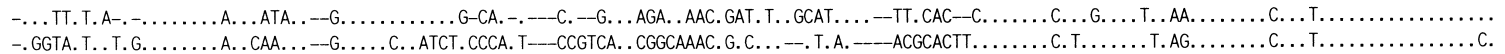

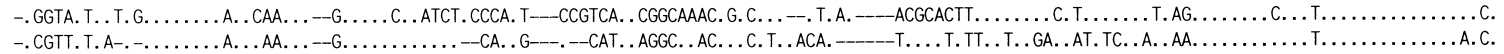

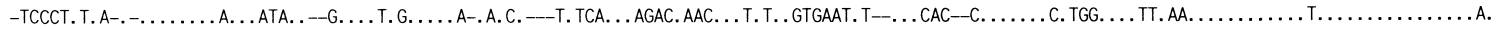

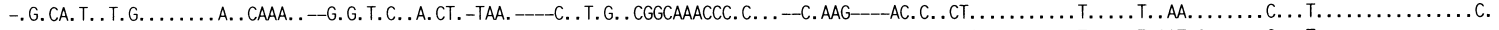

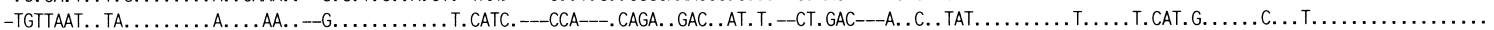

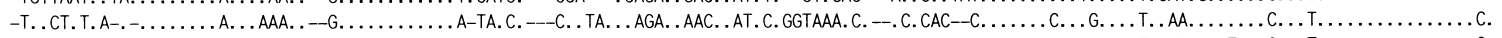

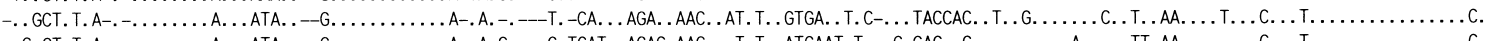

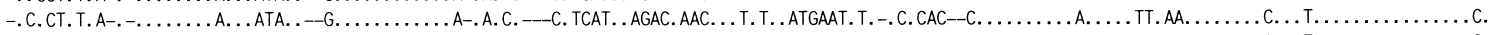

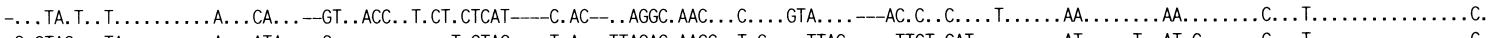

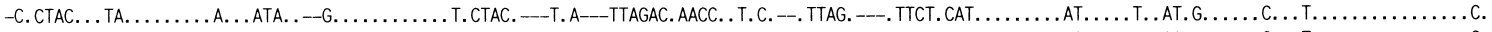

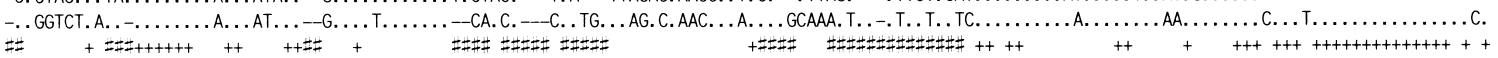

751

TCTTCTTCAAGAGTCCATATCGACAAGAAGGTTTACGACCTCGATGTTGGATCAGGACACCCAAATGGTGCAGCCGCTATTAACGGTTCGTTTGTTCAACGATTAACAGT

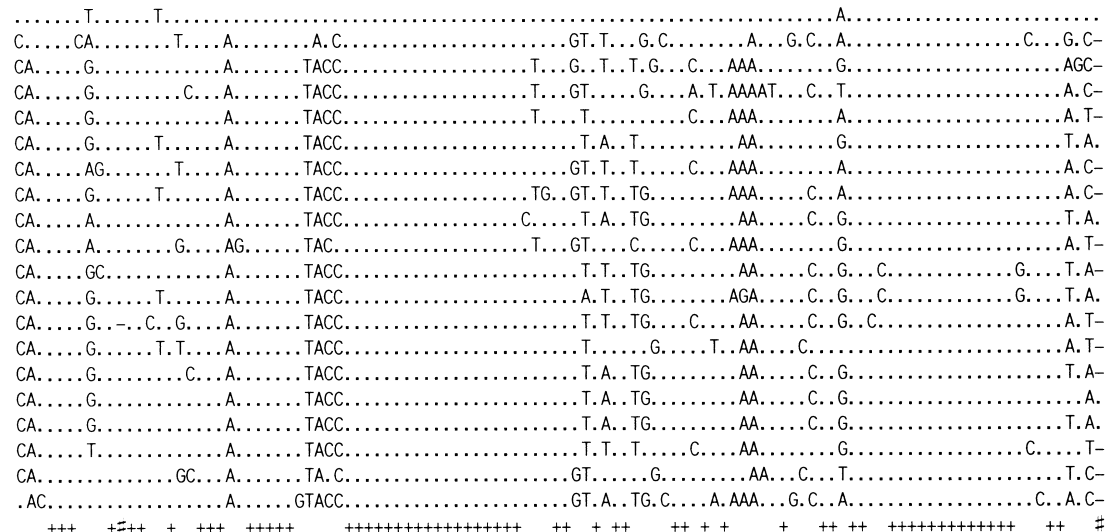

